\title{
POSTĘPOWANIE PODSTAWOWEGO ZESPOLU RATOWNICTWA MEDYCZNEGO W DRGAWKACH GORĄCZKOWYCH U DZIECI
}

\section{PROCEEDINGS OF THE BASIC MEDICAL RESCUE TEAM IN FEBRILE SEIZURES IN CHILDREN}

\author{
Zawadzki Dariusz \\ Wojewódzka Stacja Ratownictwa Medycznego w Łodzi - Rejon Zgierz
}

https://orcid.org/0000-0003-4560-0440

DOI: https://doi.org/10.20883/pielpol.2019.40

\begin{abstract}
STRESZCZENIE
Drgawki są częstym powodem wzywania zespołu ratownictwa medycznego (ZRM), zazwyczaj do osób dorosłych. Do pacjentów pediatrycznych nieco rzadziej, lecz głównie z powodu wystąpienia napadu drgawkowego z towarzyszącą wysoką gorączka. Drgawki gorączkowe występują u dzieci aż w $80 \%$ przypadków, zaś ok. $20 \%$ dotyczy drgawek jest niezwiązanych z gorączką, lecz z neuroinfekcją. Drgawki są jednym z najczęstszych stanów nagłych w pediatrii bez względu na przyczynę. Ich częstość oceniana jest na 5-8\% [1].
\end{abstract}

SŁOWA KLUCZOWE: drgawki, gorączka, dziecko, pierwszy napad drgawkowy u dziecka.

\section{Wstęp}

Podjęcie tematu drgawek u pacjenta pediatrycznego jest bardzo ważne, głównie dla członków zespołów ratownictwa medycznego (ZRM), ponieważ jako pierwsi prowadzą wywiad ze świadkiem stanu nagłego u dziecka. Często od opisu wywiadu w karcie medycznych czynności ratunkowych uzależniana jest dalsza diagnostyka pacjenta. Również ważny jest fakt, że członkowie ZRM mogą być świadkami trwającego jeszcze napadu lub kolejnego napadu drgawek w domu pacjenta. Poszerzenie wiedzy z tego zakresu jest ważne, ponieważ w dalszym etapie diagnostyki może dojść do nierozpoznania i narażenia dziecka na kolejne ataki drgawek, ale również istnieje ryzyko nadrozpoznania padaczki. Nadrozpoznanie może powodować poważne konsekwencje zarówno z punktu widzenia klinicznego, społecznego, ale i emocjonalnego. W każdym przypadku diagnoza musi zostać poprzedzona szczegółową analizą wywiadu prowadzonego zazwyczaj z rodzicami, członkami ZRM, badaniami obrazowymi oraz próbą klasyfikacji padaczki zgonie z Klasyfikacją Padaczek i Zespołów Padaczkowych [2].

\begin{abstract}
Convulsions are a common reason for calling a medical rescue team (ZRM), usually for adults, less common for pediatric patients, but mainly due to seizure with accompanying high fever. Febrile seizures occur in $80 \%$ of children and about $20 \%$ of nonfebrile convulsions, but with neuroinfection. Convulsions are one of the most common emergency conditions in pediatrics for whatever reason. Their frequency is estimated at 5-8\% [1].
\end{abstract}

KEYWORDS: convulsions, fever, child, first seizure in child.

\section{Termoregulacja}

Temperatura w warunkach fizjologicznych nie ulega znacznym wahaniom dzięki mechanizmom regulującym wytwarzanie oraz utratę ciepła z organizmu. Temperatura jest głównym czynnikiem, który wpływa na utratę ciepła [3, 4]. Wyróżnia się temperaturę wewnętrzną (mięśni, mózgu, rdzenia kręgowego, narządów wewnętrznych), która utrzymywana jest na stałym poziomie i jest mało wrażliwa na wahania temperatury, oraz temperaturę skóry, która ulega największym wahaniom. Głównym zadaniem mechanizmu termoregulacji jest utrzymanie temperatury wewnętrznej w zależności od dużych różnic temperatury otoczenia, od $15^{\circ} \mathrm{C}$ do $55^{\circ} \mathrm{C}$. W przypadku przebywania w niskiej temperaturze otoczenia organizm uruchamia mechanizmy, których zadaniem jest utrzymanie ciepła, poprzez zwężenie naczyń krwionośnych skóry, co w konsekwencji powoduje wytworzenie ciepła przez drżenie mięśniowe. W wysokiej temperaturze uruchamiane są mechanizmy powodujące utratę ciepła z organizmu przez rozszerzenie naczyń krwionośnych skóry, co objawia się poceniem, tachykardią, hiperwentylacją [3]. 


\section{Przyczyny drgawek}

- Wszystkie grupy wiekowe: hipoglikemia, urazy głowy, zatrucia, zapalenie opon mózgowordzeniowych, padaczka.

- Od urodzenia do 6 m.ż: hipoglikemia, hipokalcemia, wrodzone zaburzenia metaboliczne.

- Od 6 m.ż do 5 lat: drgawki gorączkowe, zapalenie opon mózgowo-rdzeniowych.

- Powyżej 5 roku życia: padaczka - najczęstsza przyczyna [5].

\section{Gorączka - co to takiego?}

Gorączka do końca XVII wieku była traktowana jako reakcja korzystna dla organizmu. Od XVIII dla lat sześćdziesiątych XX wieku gorączkę uznano za reakcję szkodliwą. Przez ostanie lata liczne badania naukowe udowodniły, że gorączka jest zapalną reakcją obronną organizmu $i$ jest korzystna, głównie w przypadkach chorób wywołanych przez zakażenie organizmu. Pierwsze doniesienia nt. gorączki sięgają kilku tysięcy lat przed erą nowożytną. Karl Reinhold August Wunderlich jako pierwszy przeprowadził badania dotyczące temperatury ciała i w 1868 roku opublikował swoje wyniki, ustalając temperaturę $37^{\circ} \mathrm{C}$ jako normalną oraz wyznaczył jej górną granicę $38^{\circ} \mathrm{C}$. Wg Karla gorączka powinna być uważana za objaw toczącego się procesu chorobowego, a nie chorobę. Wartości temperatury zmieniają się w rytmie dobowym. Największa wartość temperatury przypada na późne popołudnie oraz wieczór, zaś najniższa na 6 rano (wartości pomiarów mogą różnić się o $1^{\circ} \mathrm{C}$. Prawidłowa temperatura ciała wynosi $36^{\circ} \mathrm{C}-37^{\circ} \mathrm{C}$. Stan podgorączkowy to zakres temperatury między $37^{\circ} \mathrm{C}$ a $38^{\circ} \mathrm{C}$. Gorączka zostaje rozpoznana w przypadku przekroczenia $38^{\circ} \mathrm{C}$. W potocznym języku pojęcie gorączki często mylone jest $z$ hipertermią. O hipertermii mówimy myśląc o stanach spowodowanych nadmiernym ogrzewaniem dziecka poprzez okrywanie czy też ogrzewanie pomieszczeń. Warto pamiętać, że najbardziej wrażliwym narządem na zmiany temperatury jest mózg. Temperatura do $39^{\circ} \mathrm{C}$ nie dochodzi do zmian w czynności organizmu, zaś powyżej $40,5^{\circ} \mathrm{C}$ dochodzi do zaburzeń świadomości. Przy temperaturze powyżej $42^{\circ} \mathrm{C}$ może dochodzić do nieodwracalnych zmian w mózgu [3, 6-10].

Poznański pediatra Karol Jonscher uwzględnił różne przyczyny gorączki:

- zakażenia: bakteryjne (dreszcze, drgawki), wirusowe i pierwotniakowe,

- toksyny endogenne: gorączka aseptyczna (oparzenia, udar cieplny, krwawienie do przewodu pokarmowego) oraz gorączka resorpcyjna (zaburzenia wodno-elektrolitowe, zatrucia, nadmierne pragnienie),
- trucizny endogenne: gorączka polekowa (alergiczna lub toksyczna, np. po antybiotykach) oraz gorączka pirogenna,

- gorączka mózgowa: wpływ na ośrodek termoregulacji,

- gorączka uwarunkowana hormonalnie: przerost nadnerczy, nadczynność tarczycy,

- nowotwory: gorączka wywołana wzmożoną aktywnością i martwicą komórek [3].

\section{Miejsce pomiaru temperatury}

Najbardziej znanym miejscem pomiaru temperatury zarówno u dzieci, jak i osób dorosłych jest dół pachowy. Błąd pomiaru może wynikać z braku przylegania termometru do skóry kiedy pacjent się porusza. Kolejnym miejscem typowym dla pomiarów jest okolica podjęzykowa jamy ustnej. Metoda ta nie powinna być stosowana u małych dzieci, ponieważ istnieje ryzyko rozgryzienia termometru, mimo że aktualnie nie powinniśmy spotkać się z termometrami rtęciowymi. Najdokładniejszym miejscem pomiaru temperatury jest przewód słuchowy zewnętrzny, ponieważ błona bębenkowa zaopatrywana jest przez tętnicę ośrodka termoregulacji w mózgu. Pomiar w przewodzie słuchowym wskazuje wartość $37,6^{\circ} \mathrm{C}$, czyli temperaturę bliską temperatury wnętrza [9].

\section{Fazy gorączki}

Faza I - u dziecka w I fazie obserwuje się upośledzenie aktywności, uczucie zimna, brak łaknienia, brak chęci do zabawy, brak zainteresowania otoczeniem, osłabienie. Za objawy pierwszej fazy odpowiada działanie interleukiny w ośrodkowym układzie nerwowym.

Faza II - działanie podwzgórzowe powoduje wytworzenie i oddanie ciepła. Na tym etapie można obserwować poprawę stanu ogólnego pacjenta oraz zwiększenie aktywności.

Faza III - charakteryzuje się obniżeniem temperatury do wartości prawidłowej wskutek odpowiedzi mechanizmu termoregulacji do poziomu wyjściowego [9].

\section{Drgawki gorączkowe}

Według The International League Against Epilepsy drgawki gorączkowe określane są jako "napady drgawkowe związane z chorobą przebiegającą z gorączką, którym nie towarzyszy zakażenie ośrodkowego układu nerwowego, ani ostre zaburzenia elektrolitowe; dotyczą dzieci po 1. miesiącu życia, u których uprzednio nie występowały napady drgawkowe niezwiązane z gorączką". Określono dolną granicę temperatury, przy której można rozpoznać drgawki gorączkowe - jest to $38^{\circ} \mathrm{C}$ lub $38,4^{\circ} \mathrm{C}$. Główną przyczyną wystąpienia drgawek jest dynamika wzrostu temperatury, a nie tylko jej wysokość [11-12]. 


\section{Podział drgawek gorączkowych w zależności od przebiegu ich napadu}

Wyróżnia się drgawki proste oraz złożone. Drgawki proste - stanowią 90\% wszystkich napadów. Są to drgawki uogólnione z utratą przytomności. Trwają do 15 minut, najczęściej ustępują po 2-3 minutach i nie dochodzi do ich nawrotu. Drgawki złożone - trwają powyżej 15 minut oraz powtarzają się w trakcie trwania choroby gorączkowej (możliwy nawrót w ciągu doby). Drgawki te występują jedynie z zaburzeniami świadomości (brak kontaktu z dzieckiem, brak kontaktu wzrokowego). Drgawki zazwyczaj obejmują jedną połowę ciała, mogą również występować w obrębie jednej kończyny, policzka czy powieki. Po ustąpieniu może dochodzić do ponapadowego porażenia jednej lub obu kończyn, tzw. porażenie Todda (występuje zaledwie u 0,4\% pacjentów).

Dla obu rodzaju drgawek charakterystyczny jest ponapadowy głęboki sen [13-17].

\section{Postępowanie ZRM w drgawkach gorączkowych}

1. Wywiad SAMPLE i badanie ABCDE.

- $\mathbf{S}$ (signs/symptoms) - to, co widzimy a także to, co zgłasza pacjent; zapytaj o czas, okoliczności wystąpienia bólu (w spoczynku, po wysiłku fizycznym) w klatce piersiowej, nasilenie bólu, czy zmienia się podczas zmiany pozycji ciała.

- A (allergies) - uczulenia, szczególnie na leki.

- $\quad \mathbf{M}$ (medicines) - leki, jakie przyjmuje pacjent.

- $\quad \mathbf{P}$ (past medical history) - przebyte choroby, operacje, ciąża.

- $\quad \mathbf{L}$ (last oral intake) - ostatni posiłek.

Badanie ABCDE:

- A (airway) - drożność dróg oddechowych (bezprzyrządowe lub przyrządowe udrożnienie dróg oddechowych).

- $\quad$ B (breathing) - oddech (częstość, tor oddychania).

- $\quad \mathbf{C}$ (circulation) - krążenie (CRT, żyły szyjne, tętno - częstość, jakość, miarowość, symetria, BP).

- D (disability) - ocena zaburzeń świadomości (ocena źrenic, glikemia)

- $\quad \mathbf{E}$ (exposure) - wykonanie ekspozycji pacjenta - zdjęcie odzieży w celu poszukiwania ewentualnych ukrytych obrażeń ciała mogących stanowić bezpośrednie zagrożenia życia i zdrowia.

2. Jeśli ZRM zastaje dziecko podczas napadu drgawek, pierwszy postępowaniem jest podanie diazepamu $0,5 \mathrm{mg} / \mathrm{kg} \mathrm{m} . c$ do łącznej dawki $3 \mathrm{mg}$, u dziecka do 3 roku życia doodbytniczo (p.r) oraz 10 mg p.r u dzieci powyżej 3 roku życia. Jeśli zostanie uzyskany dostęp dożylny, należy podać diazepam w dawce 0,2-0,3 mg/kg m.c. Jeśli mimo podanych leków, napad drgawkowy utrzymuje się, należy postępować jak w przypadku stanu padaczkowego. Kolejno po ustąpieniu drgawek należy rozpocząć leczenie gorączki [18].

3. Jeśli ZRM zastaje dziecko po napadzie drgawek, po zbadaniu dziecka należy wdrożyć leczenie przyczynowe, czyli leczenie gorączki groźnej dla życia dziecka.

Paracetamol (czopki) w dawce 10-15 mg/kg m.c p.r

Tabela 1. Dawkowanie dożylne [18] Table 1. Intravenous dosage [18]

\begin{tabular}{|c|c|c|c|}
\hline $\begin{array}{l}\text { Masa ciała/ } \\
\text { Body weight }\end{array}$ & $\begin{array}{l}\text { Dawka/ } \\
\text { Dose }\end{array}$ & $\begin{array}{c}\text { Zawartość } \\
\text { butelki w ml/ } \\
\text { The contents } \\
\text { of the bottle } \\
\text { in } \mathrm{ml}\end{array}$ & $\begin{array}{c}\text { Czas } \\
\text { podania/ } \\
\text { Time of } \\
\text { administra- } \\
\text { tion }\end{array}$ \\
\hline$<10$ kg/kilogram & $\begin{array}{l}7,5 \mathrm{mg} / \mathrm{kg} \mathrm{m.c/miligram/} \\
\text { kilogram of body weight }\end{array}$ & \multirow{2}{*}{$\begin{array}{l}50 \mathrm{ml} / \\
\text { milliliters }\end{array}$} & \multirow{4}{*}{$\begin{array}{l}15 \text { min./ } \\
\text { minutes }\end{array}$} \\
\hline $\begin{array}{c}10 \text { kg (kilogram) - } \\
33 \text { kg (kilogram) }\end{array}$ & $\begin{array}{l}15 \mathrm{mg} / \mathrm{kg} \text { m.c/miligram/ } \\
\text { kilogram of body weight }\end{array}$ & & \\
\hline $\begin{array}{c}33 \text { kg(kilogram) - } \\
50 \text { kg (kilogram) }\end{array}$ & $\begin{array}{c}15 \mathrm{mg} / \mathrm{kg} \mathrm{m} . \mathrm{cl} \\
\text { miligram/kilogram of body } \\
\text { weight }\end{array}$ & \multirow{2}{*}{$\begin{array}{l}100 \mathrm{ml} / \\
\text { milliliters }\end{array}$} & \\
\hline$>50$ kg (kilogram) & $\begin{array}{c}1000 \text { mg, jednorazowo/ } \\
\text { miligrams, once }\end{array}$ & & \\
\hline
\end{tabular}

Źródło: opracowanie własne

Source: author's own analysis

W przypadku braku reakcji na paracetamol należy rozważyć domięśniowe lub dożylne podanie pyralginy [18]

Tabela 2. Dawkowanie pyralginy

Table 2. Dosage of pyralgin

\begin{tabular}{|c|c|c|}
\hline $\begin{array}{l}\text { Masa ciała/ } \\
\text { Body weight }\end{array}$ & $\begin{array}{c}\text { Dawka } \\
\text { jednorazowa/ } \\
\text { Single dose }\end{array}$ & $\begin{array}{l}\text { Rozcieńczenie/ } \\
\text { Dilution }\end{array}$ \\
\hline 9-15 kg/kilograms & $0,2-0,5 \mathrm{ml} /$ milliliters & $1: 10(1 \mathrm{ml}$ do $10 \mathrm{ml})$ \\
\hline $16-23 \mathrm{~kg} /$ kilograms & $0,3-0,8 \mathrm{ml} /$ milliliters & $0,9 \% \mathrm{NaCl}$ \\
\hline $24-30 \mathrm{~kg} /$ kilograms & $0,4-1,0 \mathrm{ml} /$ milliliters & $\begin{array}{l}5 \% \text { glukoza, Płyn } \\
\text { Rinqera/1 milliliters }\end{array}$ \\
\hline 31-45 kg/kilograms & $0,5-1,0 \mathrm{ml} /$ milliliters & to 10 milliliters $0,9 \%$ \\
\hline $46-53 \mathrm{~kg} / \mathrm{kilograms}$ & 0,8-1,8 $\mathrm{ml} /$ milliliters & $\begin{array}{c}\mathrm{NaCl}, 5 \% \text { glucose, } \\
\text { Ringer's liquid }\end{array}$ \\
\hline
\end{tabular}

Źródło: opracowanie własne

Source: author's own analysis

4. Płynoterapia: przed wdrożenieniem płynoterapii należy ocenić obciążenie wstępne.

Fizjologia:

- wypełnienie żył szyjnych - w normie,

- zmiany osłuchowe u podstawy płuc - bez zmian,

- brzeg wątroby - $1 \mathrm{~cm}$ poza łukiem żebrowym, 
- jeśli dziecko nie prezentuje przeciążenia wstępnego, należy podać krystaloidy w dawce $20 \mathrm{ml} / \mathrm{kg}$ m.c. Należy kontrolować obciążenie wstępne po każdym bolusie płynów!!!

O przeciążeniu wstępnym świadczą: nadmiernie wypełnione żyły szyjne, trzeszczenia u podstawy płuc, brzeg wątroby wystający więcej niż $1 \mathrm{~cm}$ poza łuk żebrowy [19].

5. Tlenoterapia przez maskę twarzową, w przepływie 4-6 I/min.

6. W przypadku stanu padaczkowego wezwij zespół specjalistyczny. Jeśli czas dotarcia zespołu specjalistycznego do pomocy jest dłuższy niż czas transportu dziecka do szpitala, należy podjąć decyzję o transporcie zespołem podstawowym, jednocześnie informując szpital o przybliżonym czasie dotarcia do szpitala.

\section{Podsumowanie}

1. Zastane przez zespół ratownictwa medycznego dziecka w trakcie napadu drgawek wymaga podania leków przeciwdrgawkowych.

2. W przypadku wystąpienia gorączki zagrażającej życiu, należy podać leki przeciwgorączkowe.

3. W zależności od czasu trwania gorączki należy rozważyć płynoterapię pod ścisłą, ciągłą oceną obciążenia wstępnego.

\section{Piśmiennictwo}

1. Sugai K. Current management of febrile seizures in Japan: an overview. Brain Dev 2010; 32: s. 64-70.

2. http://www.ptnd.pl/nd/neurologia_40-87-89.pdf [dostęp 10.05.2018 r., godz. 17:00].

3. Stopfkuchen H. pod red. Jakubaszko J. Nagłe zagrożenia zdrowotne u dzieci. MedPharm Polska, Wrocław. 2010. s. 69-72.

4. Pang D, Newson T, Budd C, Gardiner M. Crash Course Pediatria. Elselvier Urban\&Partner, Wrocław 2007, s. 314.

5. Kozak W. Geneza gorączki, Wydawnictwo naukowe Uniwersytetu Mikołaja Kopernika, Toruń 2009.
6. Rosińska A, Kabelska-Dubiel N, Cichy W. Nowe spojrzenie na problem podwyższonej temperatury ciała u dzieci, Nowiny Lekarskie. 2003, 72, 6; s. 467-472.

7. Pawłowski Z, Stefaniak J. Parazytologia kliniczna, PZWL, Warszawa 2004.

8. Wendorff J. i wsp., Drgawki gorączkowe, PZWL, Warszawa 2009, s. 11-62.

9. Mrozińska M. Zasady stosowania leków przeciwgorączkowych u dzieci. Lek w Polsce. 14, (166); s. 1-10.

10. Maciejasz P. Drgawki gorączkowe u dzieci, Pediatria po dyplomie. Wydanie specjalne, czerwiec 2008; s. 32-34.

11. Wendorff J. Postępowanie w drgawkach gorączkowych prostych i złożonych. Standardy medyczne pediatria. 2000, 2; s. 6 .

12. Addy DP. Prophylaxis and febrile convulsions. Archives if disease in childhood. 1981, 56 (2); s. 81-83.

13. Kacińska E. Drgawki gorączkowe - częsty problem neurologiczny niewymagający zazwyczaj intensywnego leczenia, ale dokładnej oceny klinicznej. Medycyna Praktyczna Pediatria. 2004, 5; s. 41-49.

14. Koyama R, Matsuki N. Novel etiological and therapeutic strategies for neurodiseases: mechanisms and consequences of febrile seizures: lessons from animal models. J. Pharmacol Sci. 2010, 113 (1); s. 14-22.

15. Steering Committee on Quality Improvement and Management, Subcommittee on Febrile Seizures American Academy of Pediatrics. Febrile seizures: clinical practice guideline for the long-term management of thechild with simple febrile seizures. Pediatrics. 2008 June, 121 (6); s. 1281-1286.

16. Valman HB. ABC of 1 to 7 febrile convulsions. British Medical Journal. 1982 May, 284 (6325); s. 1321-1322.

17. http://leki.urpl.gov.pl/ - [dostęp 10.09.2018 r., godz. 20:00]

18. Andres J. Zaawansowane zabiegi resuscytacyjne u dzieci, Kraków 2016, s. 15.

Artykuł przyjęty do redakcji: 11.10. 2018.

Artykuł przyjęty do publikacji: 29.01.2019.

Źródło finansowania: Praca nie jest finansowana z żadnego źródła. Konflikt interesów: Autorzy deklarują brak konfliktu interesów.

\author{
Adres do korespondencji: \\ Zawadzki Dariusz \\ Wojewódzka Stacja Ratownictwa Medycznego w Łodzi - Rejon Zgierz \\ ul. Parzęczewska 35 \\ 95-100 Zgierz \\ e-mail: dariusz.zawadzki@wsrm.lodz.pl
}

